\title{
Implementation of Innovation Management Systems in Large Companies of Different Typologies
}

\author{
Çağlar ÜÇLER iD a R. Işıl YAVUZ iD \\ a Faculty of Aviation and Aeronautical Sciences, Özyeğin University, Istanbul, Turkey \\ caglar.ucler@ozyegin.edu.tr \\ b Faculty of Business, Özyeğin University, Istanbul, Turkey isil.yavuz@ozyegin.edu.tr
}

\begin{tabular}{ll}
\hline ARTICLE INFO & ABSTRACT \\
\hline Keywords: & $\begin{array}{l}\text { Purpose - While established companies try to renew themselves and upgrade to innovation } \\
\text { organizations through the implementation of innovation management systems, academic } \\
\text { Innovation Management System } \\
\text { literature is scarce regarding how they actually do it and if different approaches are required in } \\
\text { different firm typologies. The purpose of this paper is to fill this research gap by presenting a 10- } \\
\text { System Implementation }\end{array}$ \\
step innovation management system that is proposed by the InoSuit project, and compare the \\
actual implementation processes of this roadmap in large and mature organizations of different \\
Research
\end{tabular}

Large Company; Typology

Design/methodology/approach - This paper employs an inductive action research approach which uses qualitative methods of data collection to produce a form of grounded theory that does not test formal research hypotheses but guides subsequent interventions in the organizations.

Received 30 October 2018

Revised 20 January 2019

Accepted ............. 2019 Authors of this paper, as mentors and researchers, spent at least half a day every week for eleven months between October, 2017 and September 2018 in the focal companies, and did several individual interviews and groups meetings in an iterative process of planning, acting and observing of the processes and consequences of establishing an appropriate innovation

Article Classification:

Research Article management system in two large organizations.

Findings - The results demonstrate that while the IMS roadmap proposed by the InoSuit project is a useful starting point, how it is actually being implemented is driven by company typology where bureaucrats run this system in a slow, cautious and centralized manner where action steps are planned in advance, incremental ideas are selected, and innovation projects are funded and implemented internally. Dynamic movers, on the other hand, implement the system much faster and in a decentralized way where employees at every level are empowered to make decisions in an iterative manner. Radical ideas are welcomed as well as incremental ideas and external cooperation is searched for both in funding and implementing the innovation projects.

Discussion - Implementing an IMS is a complex task with company specific requirements. It was observed that different approaches were required in different companies. The paper discusses the observed implementation methods, associated enablers and challenges in a comparative manner and suggests direction for future research.

\section{Introduction}

Companies innovate to achieve continuous growth (Bear, 2006). Innovation can be in the form of new products and services, processes, raw materials, business models or marketing techniques (Sawhney, 2006; Tsekouras et al., 2014). Successful innovations imply a certain upgrade of the organization (Humphrey and Schmitz, 2002; Ucler, 2017), facilitated by the change of existing practices. This further leads to management innovation and a new organization (Birkinshaw, et al., 2008). So, while innovation is the key driver to change, the change in the organization does drive innovation.

\section{Acknowledgements}

This research is utilizing knowhow and experiences accumulated during the InoSuit Project, which is initiated and funded by the Turkish Exporters Assembly (TIM) to support competitiveness through innovation in the international market place. The author would like to thank all stakeholders of the project. 
In order to be innovative, organizations often implement Innovation Management Systems (IMS) such as described in (CEN/TS, 2013). Implementing such systems requires a lot of time and harmonized efforts. Also, the implementation of IMS differs with respect to the company size based on their differences in the innovation scene (Acs and Audretsch, 1988). Large companies are generally better prepared for innovation with their advantages of scale (Nieto and Santamaría, 2010), but it is also obvious that size might become a disadvantage due to the hierarchies yielding in bureaucratic decision making, low-powered incentives, or principal-agent distortions (Teece, 1996). On the top of this, the differences in job practices, organizational culture, ownership structure and customer types also require different types of organizational arrangements to for successful implementation of IMSs (Teece, 1996; Gudmundson et al., 2003).

This paper seeks to understand how IMS are actually implemented in large companies and how the implementation of IMS needs to be adjusted based on two different company typologies: bureaucrats and dynamic movers. We use the term bureaucrats to refer to mechanistic type of organizations characterized by high formality, high centrality, high stratification and high degree of bureaucracy while we use the term dynamic movers for organic type organizations characterized by low formality, low centrality, low stratification, and dynamic climate (Schie et al., 1996; Burns \& Stalker, 1950). The paper uses action research (Lewin, 1946; Argyris \& Schon, 1974, Eden \& Huxam, 1996) to draw insight from the InoSuit Project, an innovation focused mentoring project in collaboration and ownership of Turkish Exporters Assembly (TIM). The authors participate in this project as mentors and researchers and work with companies to establish an appropriate IMS.

The results suggest that while the IMS roadmap is a useful starting point, how it is actually being implemented is driven by company typology where bureaucrats run this system in a slow, cautious and centralized manner where action steps are planned in advance, incremental ideas are selected, and innovation projects are funded and implemented internally. Dynamic movers, on the other hand, implement the system much faster and in a decentralized way where employees at every level are empowered to make decisions in an iterative manner. Radical ideas are welcomed as well as incremental ideas and external cooperation is searched for both in funding and implementing the innovation projects.

The structure of the paper is as follows. First, the IMS and the roadmap for the IMS implementation are explained. Then, the two companies exemplifying the variations and the method including the comparison based on experience from the InoSuit Project are described. After that, the implementation, associated challenges and best practices obtained are discussed in a comparative manner.

\section{Innovation Management System Roadmap and Typologies}

Innovation is the generation of added value over new ideas and it is bounded with commercial outputs (Jacobides et al., 2006; 2017). The collection, evaluation and the transformation of new ideas into innovations has to be continuously done by integrating different departments (Morris, 2011) so that employees with different skill sets can exchange explicit as well implicit knowledge iteratively (Nonaka et al., 2000). Consequently, a concurrent engineering environment is required, integrating ideally all stakeholders of the value chain. This is assured by the IMS with its structured processes and procedures.

Both intensity and crystallization are required to succeed at innovation (Ahmed, 1998). This means that all divisions should put strong effort in the innovation processes. This can be achieved by using innovation management systems (IMS), streamlining systematically ideation with strategic perspectives yielding in object and subject innovation (Karlsson, 2013). This is simply the formalization of the process of innovation, where strategy guides but also is revised based on the idea portfolio and the research base. That is, IMS structures the innovation processes and enables new product/ service innovation, as well for other types of innovations.

A typical IMS includes knowledge management, market intelligence, cooperation and networking, human resources management, interface management, creativity development, process improvement, innovative project management, design management, and new business creation (Mandić, 2014). Thus it is a total approach, integrating several tasks. While there are different IMS implemented in different organization, we present the IMS Implementation Roadmap prepared in the context of InoSuit Project as shown in Figure 1. 
The project proposes first an analysis of the company, then trainings to enable common terminology, which is followed by upgrades in the infrastructure that then leads to ideation and realization of innovation projects.

The roadmap of the InoSuit Project (2016) is generated by experts from academy and industry to reach the innovation objectives within the Turkish Innovation Strategy 2023 (TIM, 2016). It delivers a systematic approach enabling traceability within a collaborative environment and aims to "support innovation capabilities to enhance the competitiveness of Turkish exporters by innovation" (Ucler and Adiloglu, 2018). The implementation is made by the companies themselves, where mentors from academia support them with weekly meetings for training, planning and review. Every three months, all participating companies and the mentors get together for experience exchange and the project office keeps record and gives support based on monthly progress reports. The total duration of the project is eleven months. The project is now ongoing program with four distinct application times in January, April, July and October. The program is supported by governmental funds, and until now there are over 232 applications from 36 cities and the mentor pool does contain 601 academicians from 97 universities (UND, 2018).

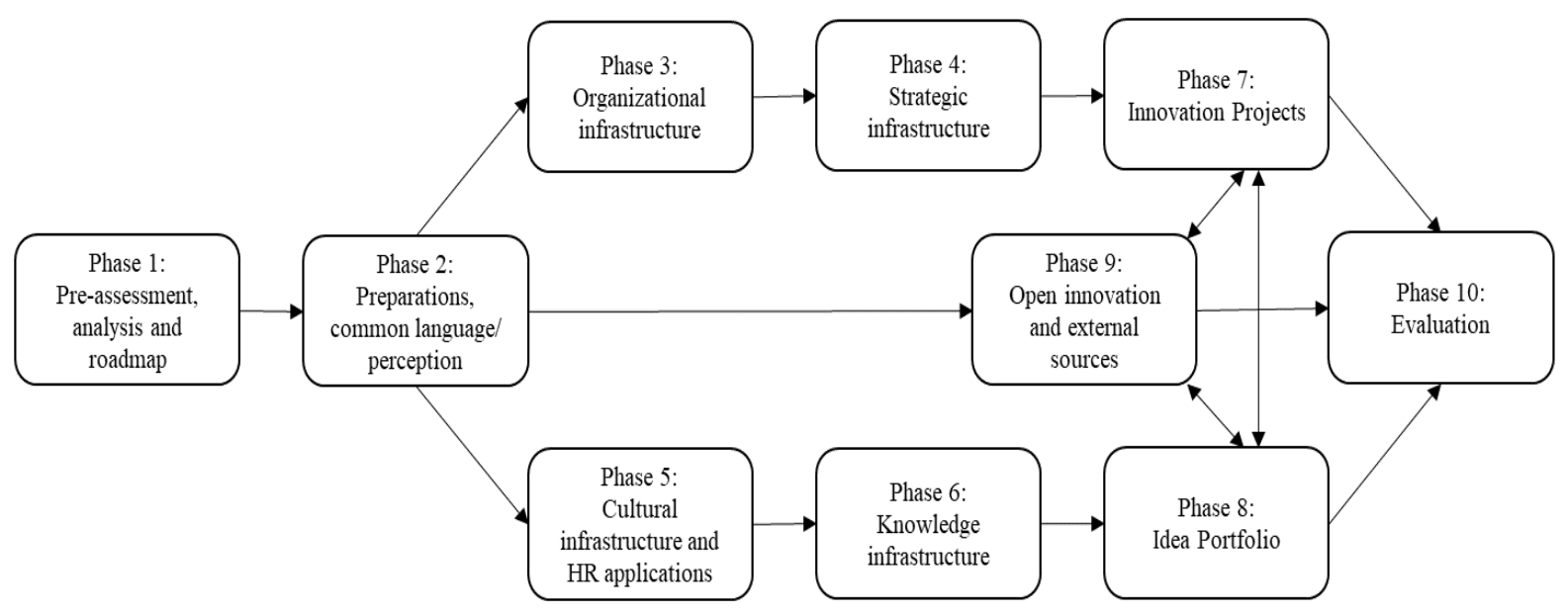

Figure 1: IMS implementation roadmap of InoSuit Project, (retrieved from Ekmekci and Pasin, 2016)

The roadmap itself is generic and contains successive tasks, undertaken in a loose order, i.e. depending on the capabilities of companies, the precedencies or concentrations can be varied by the mentors. Therefore, it starts with an analysis of the company utilizing several scorecards (e.g., USIMP, 2017; AT Kearny, 2017; CEN, 2013). After that, the second phase assures with trainings and meetings that all stakeholders utilize the same language for innovation. Then with the support of the upper management the organizational, strategic, cultural and knowledge infrastructures are to be reengineered. This means extensive work on processes, procedures, information technology (IT) systems enabling the appropriate environment for the innovation stream, which then will be leveraged to realize innovation projects selected from the generated idea portfolio. Last but not least, the utilization of external resources and open innovation options are assessed and an evaluation of the whole IMS is done at the final stage.

While InoSuit IMS Implementation Roadmap is a useful starting point, the successful implementation of IMS requires company specific aspects to be respected. Therefore, the project requires researchers as mentors to analyze each company and then develop appropriate implementation practices that can be different from the initial roadmap. While each company is unique, a useful grouping of companies can be made based on size, which is naturally bounded to the industrialization stage. According to Tsekouras et al. (2014), new establishments are mainly in the pre-industrialized phase, while large industrialized companies are either trying to expand consolidated or at a renewal stage; there is a permanent move between these stages and all innovation efforts specifically address the designated stage. Another typology is related to the company culture/ climate and design. E.g. Ionescu and Bratosin, (2009) did conclude that there is a variation with regard of the pre-existing culture type as power-oriented, role-oriented, task-oriented and person-oriented, when they were looking at the implementation of quality management systems. This indicates a good fit to the IMS implementation as well: similarly, organizational culture and climate are determining innovation outputs (McDermott \& O'Connor, 2002; Ahmed, 1998). 
Consequently, during the implementation of this roadmap, a relaxation of this framework is necessary so that the IMS' requirements and their implementation can have long lasting effect in the organization. When looking particularly on large companies, variations are observed in their organizational design, culture and business practices, which have profound effects on implementation (Vaccaro et al., 201). Accordingly, this paper suggests two typologies of large companies based on design, culture and business practices, where associated appropriate approaches for the implementation of IMS are observed to be very similar: bureaucrats and dynamic movers. The first typology is bureaucrats that tend to be mechanistic organizations with high formality, centrality of decision-making, high stratification among departments, and high degree of bureaucracy. The other end of the continuum is the dynamic movers that tend to be organic organizations with low formality, decentralized decision making, blurred boundaries between departments, and dynamic climate (Burns \& Stalker, 1959). These two types of organizations described in the literature fit well with the companies observed in the context of InoSuit Project for IMS implementations, which will be explained next.

\section{Method}

This study is rooted in action research (Lewin, 1946; Argyris \& Schon, 1974, Eden \& Huxam, 1996), which refers to the "the research output that results from an involvement with members of an organization over a matter which is of genuine concern to them" (Eden \& Huxham, 1996, pg.75). Action research is a collaborative effort undertaken by the active participation of researchers and organizational members with a common purpose (Koshy, Koshy \& Waterman, 2010). As such, it is a situation-based and context -specific research that develops reflection based on interpretations made by the participants and the knowledge created through action and at the point of application and are not necessarily conclusive or absolute for all organizations (Dickens \& Watkins, 1999). Action research involves an iterative cycle of planning a change, acting and observing the process and consequences of change in order to learn and plan subsequent actions (Dickens \& Watkins, 1999). Accordingly, authors of this paper, as mentors and researchers, spent at least half a day every week for eleven months between October, 2017 and September 2018 in the focal companies, and actively participated in the planning, acting and observing of the processes and consequences of establishing an appropriate innovation management system in two large organizations that took part in the InoSuit Project.

While there are several different categories of action research practices, this paper follows an inductive action research practice which uses qualitative methods of data collection to produce a form of grounded theory that does not test formal research hypotheses but guides subsequent interventions in the organizations (Caseell \& Johnson, 2006). In this method, managers and employees were interviewed individually and several groups meetings were conducted. Moreover, survey instruments including ÜSIMP Innovation report card, IMP3rove survey of AT Kearny (2017), IMS check list of (CEN/TS, 2013), lifecycle approach of Tsekouras et al. (2014), the innovation value chain assessment of Hansen and Birkinshaw (2007), and the questionnaire for existing innovation methods and tools as indicated by Hidalgo and Albors (2008) were administered to all members in both companies. Additionally, more than 30 InoSuit mentors did meet formally every three months for experience exchange. Also there were advisory board meetings for further discussions of difficulties and precautions/ changes to be implemented to fine-tune the roadmap. The learnings of the authors gathered in all of these meetings were reflected here as well.

After initial data collection, the authors of the paper and relevant individuals in the focal organizations analyzed it, and co-designed an initial IMSs for each organization. As these systems were being implemented, the processes and the results of implementation efforts were observed and discussed, and the changes were made in these design iteratively several times. The results presented here indicates the final state of IMSs in these two large companies. These companies are called here as Company A and Company B for confidentiality reasons ${ }^{1}$. Both companies are involved in production, and they both have an annual turnover over 500 million US\$. According to the Nasdaq's Industry Classification Benchmark (ICB) by the FTSE Group (FTSE Russell, 2017), Company A is operating in the sector of Basic Materials and Company B is in Consumer

\footnotetext{
1 The mentors and the companies signed a confidentiality agreement at the start of the InoSuit project, which outlaws authors from revealing the name of the companies for confidentaility reasons. However, the paper provides enough information about these companies to serve its scholarly purpose.
} 
Staples. The employees in both companies are unionized. They both have in-house production, which they market internationally.

While Company A is at the Stock Exchange Market with mainly national shareholder structure, Company B has an international partner, but is not on the stock market. They both do have investments and affiliations worldwide (See Table 1).

Table 1: Company Descriptions

\begin{tabular}{|l|c|c|}
\hline & Company A & Company B \\
\hline Typology & Bureaucrats & Dynamic movers \\
\hline Annual Turnover & $>1 \mathrm{~b} \$$ & $>0.5 \mathrm{~b} \$$ \\
\hline Sector & Basic Materials & Consumer Staples \\
\hline Number of Employees & 850 & 2595 \\
\hline Number of Physical Locations & 11 & 18 \\
\hline In-house Production & Yes & Yes \\
\hline International Partners & No & Yes \\
\hline International Investments & Yes & Yes \\
\hline Union & Yes & Yes \\
\hline Owner managed & No & Yes \\
\hline
\end{tabular}

\section{IMS Implementation for Different Company Typologies}

It is identified that there was no firm-level innovation related policies, definitions or procedures in both companies. Both companies were trying to increase their quality level and innovativeness by leveraging inbound requests. They were focusing mainly on cost reduction, and they did partially apply total quality management (TQM) approaches for job shop optimization. The associates of both A and B were used to work in cross functional teams. In both companies, there were attempts of idea proposal systems, which did not succeed to include the whole organization on continuous base. Research and development (R\&D) division did exist in both organizations, but functioning in an isolated manner without high interaction with the environment. The R\&D divisions did work reactively on requests of other divisions or customers/ prospects that only market pull was responded to. Nevertheless, new product development (NPD) was being undertaken in both companies. The market of Company A was dominated with traditional products, while Company B was operating in a changing competitive environment. Moreover, they both did utilize enterprise resource management tools and limited information communication technologies (ICT), mainly for internal purposes. Virtual collaboration was not applied in any of them and there was no innovation culture in both companies.

Company A was found to be conservative against knowledge exchange across organization boundaries. They tried to listen to/ reflect the environment passively, but the collaboration culture with external parties was weak. There were many procedures almost for any task, which were strictly followed. Strategic perspectives were given, but not streamlined in a flow to lower levels. Company A was managed by professional managers only, but only the upper managers made decisions, and there was a high power distance. Centralized decision making was being made with cumulative data gathered from different divisions. New products did contribute only to a small fraction in the income.

Company B, on the other hand, was open across its borders, adoptive to the environment. Procedures were given, but applied on a flexible basis. General strategy was defined, but not with crunchy details. The company was managed by the owner family at the highest level together with professional managers. The organizational structure was not rigid and changes and restructuring attempts were done continuously. There were many local managers, operating freely within their job descriptions that decisions were taken locally. The communication across these local units was week, further decreased by the spatial diversity.

In both companies, new products were mainly new to the company and new processes were only new in the national market. Company A did perform slightly better than B in the usage of knowledge management and 
process enhancement tools, but preferred long lasting practices. The management of Company B was much more open to change, but the organization was conversion poor with slow diffusion rates of ideas, which reduces the innovation output (Hansen and Birkinshaw, 2007). There were hierarchical levels in both organizations, but managers including the owners of Company B were more accessible. Due to the rigid and mechanistic organizational structure and the management culture, Company A was referred to as a bureaucrat. Since the Company B was on continuous change with a more organic organizational design, it was referred to as a dynamic mover. Next section will explain how the 10-step IMS Implementation Roadmap is implemented in these two companies.

\section{Implementation of IMS Road Map for Company A and Company B}

\section{Step 1 \& 2: Pre-analysis and roadmap, preparations, common language/perception}

In both companies there were no specific objectives or innovation targets in procedures and job descriptions initially. Hence, extra-role behaviors were required for innovation, which is usually perceived as help by the associates (Van Dyne and LePine, 1998). To support this, transformational leadership and psychological empowerment is required (Pieterse et al., 2010), and the upper management has to pull the organization towards innovation by clear targets and priorities (Stamm, 2003). Consequently, the project launch was made in both typologies with general innovation training with the support of the top management. Since the training and encouragement has to be on continuous base for innovation planning (White and Bruton, 2010: 115), the human resources (HR) division was requested to support the implementation.

In the bureaucratic typology, the HR planning was structured and done in advance. As long as it was not included in annual plans, transformational incentives were not part of operations. The planning of such actions were also challenging with the high number of stakeholders. Thus all training packages for the IMS had to be determined in advance and negotiated with the upper management. A top down application enforced the continuity through the whole process. In contrast, the dynamic movers were highly adoptive and were open to change their plans on agile basis. This was leveraged to determine training packages to the specific needs of the company during the implementation. This agile approach enabled the increase of the quality of the training.

\section{Step 3: Organizational Structure}

To support the organizational infrastructure, a board for innovation, transformation and development was set with an asymmetric team composed from different levels and qualifications. While the bureaucratic company was able to self-organize and selected its members organically, the members were assigned by the upper management in the dynamic mover company. However, the dynamic movers did organize themselves and were capable to change this composition when it was required.

In both cases the teams were cross-departmental including members to support the four dimensions of business innovation as offering, process, distribution and customer (Tsekouras et al., 2014). After team composition, the procedures and instructions of the boards were generated by the boards themselves. In both cases, the innovation board did place itself to an advisory position for the upper management. There was a difference in the feedback and control mechanism. While the bureaucrats did rely on long time intervals, the dynamic movers did prefer a higher feedback frequency to involve the upper management. Also the upper management of dynamic mover company was actively contributing to the work done in the board, which accelerated formalities in an agile manner.

\section{Step 4: Strategic Infrastructure}

Many companies lose their leading position when not managing disruptive innovations or adopting market change well (Bower and Christensen, 1995). This is partly due to the lack of strategic foresight and planning, which is streamlined with operational activities (White \& Bruton, 2010: 90, 102). Consequently, the strategic infrastructure was focused on during the IMS implementation in both typologies. Both companies did have strategic planning, but in both cases there was no new product development roadmap based on that. This was assumed to be an outcome of missing IMS, and complementary to the standard strategy tools, technology 
road mapping (see Figure 2) was applied to understand the market pull and technology push (Phaal et al., 2004). The effects of technology transfer on the S-curves were also incorporated in both companies (Christensen, 2013).

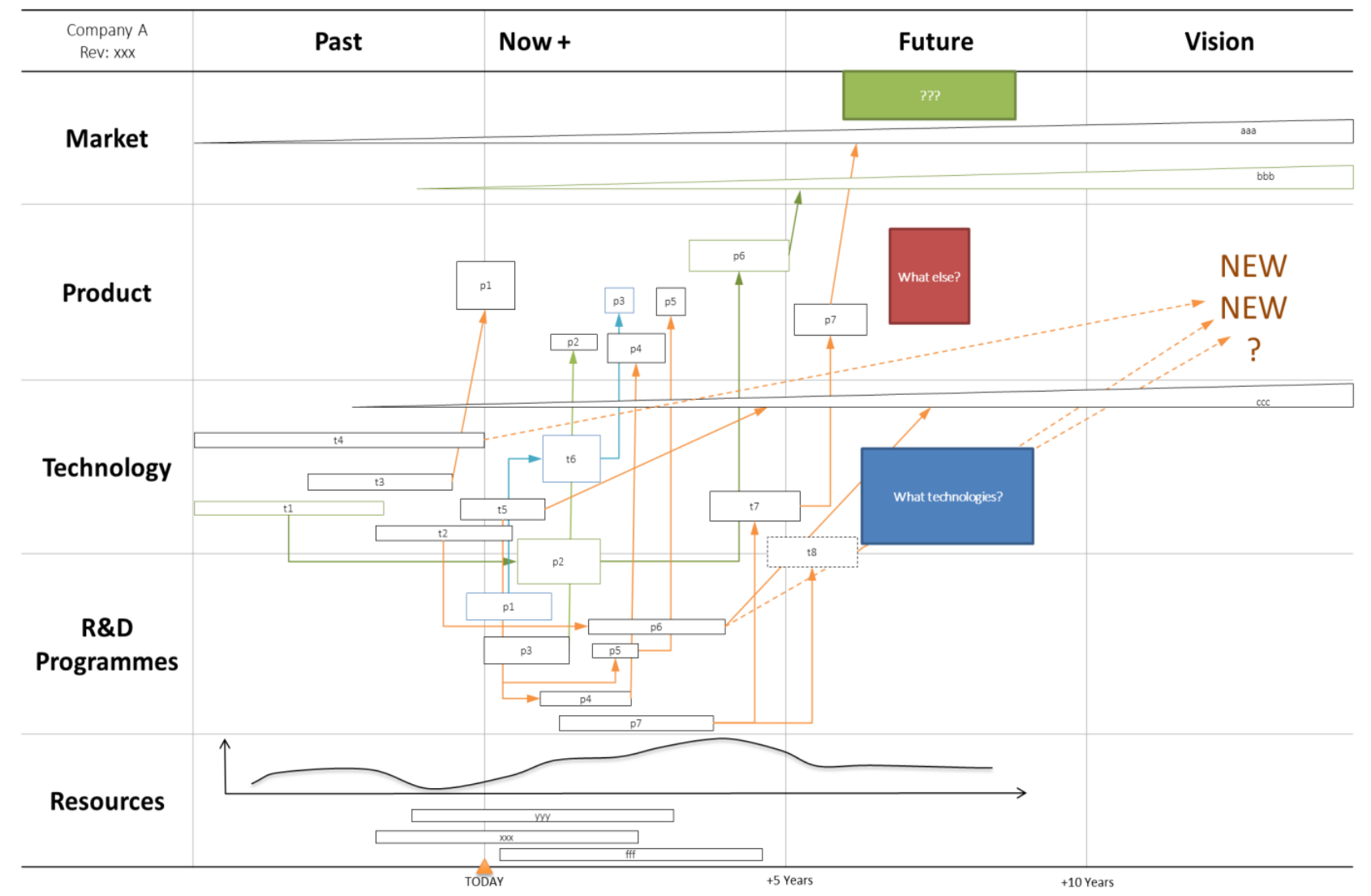

Figure 2: Strategic Roadmap of Company A

The technology roadmap given here is modified due to confidentiality reasons and is consequently of generic nature. Nevertheless, the process how it was retrieved within distinct typologies is of interest: In both companies, first a training program was organized, where the roadmapping was explained with illustrative examples. Then in Company A it was filled out in an iterative manner, where the first iteration was within $R \& D$ team and the other iterations involved members of the innovation board. It was observed that the methodology was well understood by the R\&D, but other divisions did have difficulties in internalization of it. There was also lack of support by the upper management. They did use their own tools for strategy and didn't prefer to share details with the other associates. There was practically no information flow downstream the hierarchy and there was lack of harmonization of efforts. So, some of the work was only nice to have and didn't have a high impact on the general strategy in short term. However, in Company B, the work did affect the calls for ideation. There, it was done from the beginning in conjunction with the board for innovation. It did take there a longer time to prepare it, but at the end the involvement of upper management during its preparation did lead the way. The whole team did pull the process, and there was a clear ownership in the dynamic movers.

\section{Step 5: Knowledge Infrastructure}

Typically, shared context has to be evolved for innovation (Nonaka et al., 2000). This can be managed by the IMS (CEN/TS, 2013), which facilitates ICT for knowledge management to enable a transparent and collaborative environment for the transformation of ideas into innovation outputs. As a result, ideation and idea selection, i.e. portfolio management (Stamm, 2003) and their further development into new product development and innovation outputs are systematic but complex processes starting from the fuzzy front end (Koen, 2007). 
Company A and B were consolidated initially within a linear process for the NPD initiated by customer pull. Thus, a stage-gate system for NPD (Cooper, 1990; Cooper, 2008) was conceptualized for proactive ideation through product realization, and this was implemented into the idea proposal system using ICT. While the regular stage-gate relied on a screening after scoping, problem statements or incomplete ideas were also accepted, which were further developed by the innovation board. During this idea development, extension to adjacent possible by recombination of existing innovations (Johnson, 2010:41) was also targeted by leveraging these problem definitions. The consequent screening was based on the strategic pillars of Kurt et al. (2017), assessing the ideas for value, applicability, contribution to innovation, generalization, strategy, risks and the suitability of existing solutions with analytical hierarchical processes (AHP).

\section{Step 6: Cultural Infrastructure and HR Applications}

The implemented new system did not work efficiently in Company A, because the bureaucratic approach did require approvals or decisions by the upper management: The board of innovation was not accepted as a decision maker since it was composed by associates of several organizational levels that suggested ideas needed to be reevaluated. Some selected ideas were reconsidered for further development on continuous base that loops reduced the effectivity (see Figure 3). Since the feedback frequency was low involving long inactive periods, the bureaucrats did loose valuable time waiting for decisions. A similar stage-gate approach was made for Company B, where idea development was supported as well. However, Company B was relying on intuitive work of distinct teams: Agile project management practices such as the usage of product vision instead of a well-defined product, simple iterative planning, self-managed and self-directed teams, and frequently applied monitoring and planning updates (Conforto et al., 2014) were observed.

The environment in Company B was more relaxed and local responsibilities and local decisions did enable an agile product development, which delivered flexibility in uncertain environments with unstable needs (Thomke and Reinertsen, 1998). Since the development of agile manufacturing requires among others virtual enterprises and rapid partnerships (Gunasekaran, 1999), these fields were proposed as a further development area for Company B. In fact, agile project management practices and methodologies are especially suitable in the case of development of highly innovative products (Conforto et al., 2014) that both companies can benefit from them. Both have required ICT systems, but the culture of Company A is not ready for this level autonomous empowered workers. Consequently, bureaucrats were suggested to initiate first a cultural transformation, while dynamic movers were suggested to implement agile methodologies, since they have the required absorption capability for agile.

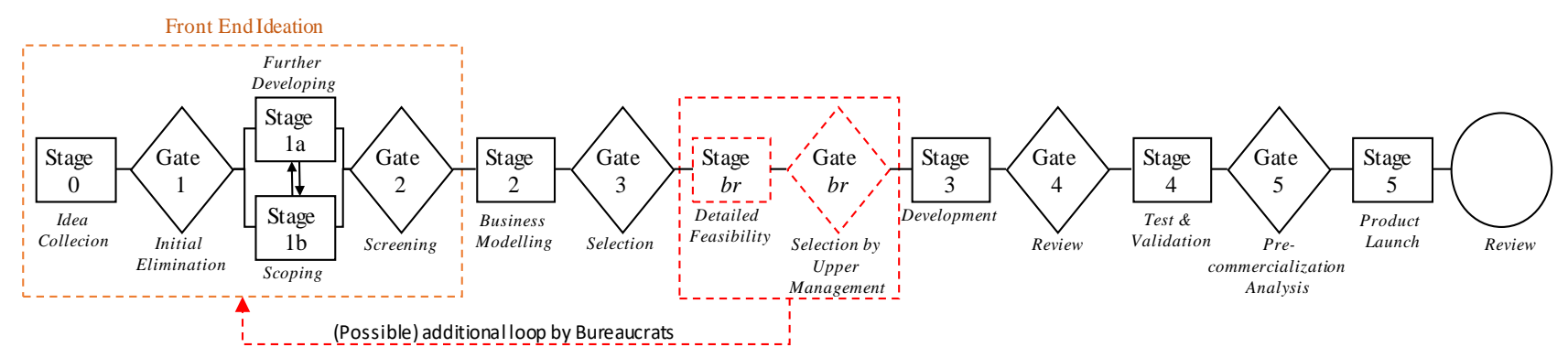

Figure 3: Stage-Gate System of (Cooper, 2008) in action: loop by Company A

\section{Step 7: Idea Portfolio}

Company B was much more open to new ideas that they had various innovation levels in the portfolio. Although, some of the upper management were not willing to share knowledge with external parties in the first place, they were all open to joint knowledge creation, given strategic focus was maintained. Consequently, both companies did prefer to remain focused. However, there are strategic buckets for diverse innovation ranging from incremental improvements to bold, new to the world innovations (Cooper, 2011). While there is a need to include both incremental and radical innovations in innovation portfolio management (Chao and Kavadias, 2008), how these two companies approached the formation of an innovation portfolio was different. 
The external mentoring in the innovation board for Company A was facilitating, but all efforts for radical innovation ideas were considered to be negotiated directly with the upper management. The bureaucrats' top management did respond in a positive manner, but wanted to see structured plans to even start small scale initiatives. The dynamic mover, on the other hand, was triggered easily with good ideas and started to invest time. They even tried to include the total value chain starting from the supplier into the innovation stream.

\section{Step 8 \& 9: Innovation Projects, Open Innovation \& External Sources}

In both cases the business model generation was conceptualized with the Business Model Canvas (BMC) of Osterwalder and Pigneur (2010) for selected ideas. It was used for totally new ideas to explore key activities, partners and resources versus customers, their relationships and channels around the centralized value proposition based on the costs and revenue structure. Both companies did like the approach, but there were deviations in the application. While Company A was comfortable with proposals in the extension of their capabilities, they did not prefer to go after bold innovations. Despite agreeing on that they have a critical mass for mergers and acquisitions, they were not open to external cooperation and/ or acquisitions that the transfer of technology and knowledge was limited. This might be a company specific issue, but an unwillingness to enter new complimentary businesses was observed. Even project proposals enhancing existing technical capabilities were accepted over a longer period when at all.

\section{Step 10: Evaluation}

Evaluation step requires how well IMS systems are successfully institutionalized and the extent to which innovations projects are implemented successfully with tangible innovation outcomes. Although longer time periods are needed to assess the eventual success of IMS systems, it is observed that establishing an IMS system in Company A was harder, more time consuming because the hierarchical culture of Company A. However, with the modifications made in the original IMS implementation roadmap, they slowly started to adopt the system whereby they have produced fewer number but larger scale innovation projects, whose outcomes have yet to be seen.

Company B, on the other hand, easily adopted the IMS system and engaged in many large and small scale innovation projects. However, innovation projects were likely to take the backseat when other issues became more important, and when the agenda changed. So, the continuity of the projects was a constant risk. However, the final outcomes of these projects have also yet to be seen. The comparisons of Company A and Company B in implementing IMS are summarized in Table 2.

Table 2: Comparison of Company A and Company B in Implementing IMS.

\begin{tabular}{|c|c|c|c|}
\hline \multicolumn{2}{|c|}{ Phase } & \multirow{2}{*}{$\begin{array}{l}\text { A (Bureaucrats) } \\
\text { Same }\end{array}$} & \multirow{2}{*}{$\begin{array}{l}\text { B (Dynamic Movers) } \\
\text { Same }\end{array}$} \\
\hline 1 & $\begin{array}{l}\text { Pre-assessment, } \\
\text { analysis and } \\
\text { roadmap }\end{array}$ & & \\
\hline 2 & $\begin{array}{l}\text { Preparations, } \\
\text { common } \\
\text { language/ } \\
\text { perception }\end{array}$ & $\begin{array}{l}\text {-Mainly in general } \\
\text {-HR did support } \\
\text {-Team members were invited directly }\end{array}$ & $\begin{array}{l}\text {-Distinct locations were visited } \\
\text {-Corporate communication did } \\
\text { support } \\
\text {-Video conferencing \& ICT facilitated } \\
\text {-Managers did gather their teams for } \\
\text { meetings }\end{array}$ \\
\hline 3 & $\begin{array}{l}\text { Organizational } \\
\text { infrastructure }\end{array}$ & $\begin{array}{l}\text {-Innovation board was set with an } \\
\text { asymmetric team, but portfolio } \\
\text { management and rewarding was by } \\
\text { existing division managers } \\
\text {-No change allowed in existing system } \\
\text {-Poor upper management visits with long } \\
\text { cycle }\end{array}$ & $\begin{array}{l}\text {-Innovation board was set with an } \\
\text { asymmetric team with decision } \\
\text { power } \\
\text {-Reengineering of positions with } \\
\text { managers } \\
\text {-Continuous upper management } \\
\text { meetings (each } 10 \text { min max) } \\
\end{array}$ \\
\hline
\end{tabular}




\begin{tabular}{|l|l|l|l|}
\hline 4 & $\begin{array}{l}\text { Strategic } \\
\text { infrastructure }\end{array}$ & $\begin{array}{l}\text {-Strategy was firm \& fixed } \\
\text { not streamlined with the bold innovation } \\
\text { claims } \\
\text {-However, R\&D team did support well } \\
\text { (champion for innovation) }\end{array}$ & $\begin{array}{l}\text {-Strategy existed but supplementary } \\
\text { strategies developed together with } \\
\text { the team } \\
\text {-R\&D team was focused too much on } \\
\text { daily routines } \\
\text {-No specific innovation champion } \\
\text { was there }\end{array}$ \\
\hline 5 & $\begin{array}{l}\text { Knowledge } \\
\text { infrastructure }\end{array}$ & $\begin{array}{l}\text {-Slow but maintaining ideas } \\
\text {-Implementation of in-house codes in the } \\
\text { MRP system (close to outside) }\end{array}$ & $\begin{array}{l}\text {-Conversion poor with slow diffusion } \\
\text { rates } \\
\text {-Implementation of in-house, web } \\
\text { based codes }\end{array}$ \\
\hline 6 & $\begin{array}{l}\text { Cultural } \\
\text { infrastructure } \\
\text { and HR } \\
\text { applications }\end{array}$ & $\begin{array}{l}\text {-Empowerment done, but needs a longer } \\
\text { time } \\
\text {-Emphasis on transformational leadership } \\
\text { required. Upper management meetings to } \\
\text { support this }\end{array}$ & $\begin{array}{l}\text {-Empowerment done successfully } \\
\text {-Change is daily routines, HR team } \\
\text { did support it }\end{array}$ \\
\hline 7 & $\begin{array}{l}\text { Idea Portfolio } \\
\text {-Stage Gate for multicriteria selecting } \\
\text { better ideas, cutting off the others }\end{array}$ & $\begin{array}{l}\text {-First elimination for (unethical; or } \\
\text { out of strategy) } \\
\text {-Then Stage Gate with simple criteria } \\
\text { for eliminating }\end{array}$ \\
\hline 8 & $\begin{array}{l}\text { Innovation } \\
\text { Projects }\end{array}$ & $\begin{array}{l}\text {-Long lasting projects, lack of fast cycle } \\
\text { projects }\end{array}$ & $\begin{array}{l}\text {-Fast cycle small projects, lack of long } \\
\text { lasting projects that strategic } \\
\text { roadmap was used to purge it }\end{array}$ \\
\hline 9 & $\begin{array}{l}\text { Open } \\
\text { innovation and } \\
\text { external sources }\end{array}$ & $\begin{array}{l}\text {-Mainly internal, only some suppliers } \\
\text { involved }\end{array}$ & $\begin{array}{l}\text {-Supply chain, customers, } \\
\text { universities, students involved }\end{array}$ \\
\hline 10 -Slow implementation of IMS & $\begin{array}{l}\text {-Fast implementation of IMS } \\
\text {-Many large and small scale projects }\end{array}$ \\
\hline
\end{tabular}

\section{Concluding Discussions}

This study set out to document the experiences and insights from the InoSuit Project regarding how two different types of companies implement IMS system differently. Specifically, it was observed that the bureaucrat company (Company A) implemented the project in a step by step fashion where HR department did the planning for these steps, including the establishment of the innovation board, which did not have much decision power, but had advisory role to division managers, who managed the innovation portfolio and performance appraisals for the innovation projects. Strategic direction was fixed and not adjusted to radically to new directions. Within the existing strategic framework, R\&D team had very strong role in supporting innovation. Few but large scale projects were selected for implementation. The hierarchical nature of the company limited initiatives at lower levels and slowed down the innovation processes. Most innovative work was done within the company boundaries with limited involvement of outside partners.

The dynamic mover company (Company B), on the other hand, was much more flexible in its approach to innovation. As such, innovation board was formed up with people involved at different levels of the hierarchy and produced large and small projects of various forms. All departments were involved in the innovation and decisions were made at every level of the hierarchy. Moreover, company B was very open to outside collaboration.

The novel contribution of this work is the approach proposing distinct applications for different typologies. To the best knowledge of the authors, there is no attempt to cluster company typologies with respect to the implementation of innovation management systems. There is only limited work for company life cycles and innovation sources, but no total approach. Which is also a managerial implication, i.e. this work gives an overview of the implementation of the innovation management system and is an illustrative example. 


\section{Limitations and Implications for Future Research}

In this paper, observations and experiences from InoSuit Project were presented regarding how 10-step IMS Implementation roadmap developed by InoSuit Project was implemented in two different large companies. This study uses and action research approach and did not intend to test any hypothesis. Instead, objective was to explore the similarities and differences between bureaucratic and dynamic mover companies in their implementation of 10-step IMS Roadmap in order to get a deeper understanding about IMS implementation in large companies that cannot be easily quantified (Maxwell, 1996). Therefore, it is important to note that the findings presented in this paper are not generalizable. They represent the learning through action research that should enrich the theory and shed a better light on future studies. One important implication of this study for future research is to examine how whether implantation of IMS system help transform these large organizations into innovative organizations. While some recent research has started to examine quantitatively how IMS affect innovation outcomes as moderated by industry characteristics (AlborsGarrigos et al., 2018), we suggest that future quantitative studies also examine the effect of IMS systems on innovation as moderated by company characteristics.

Established organizations need to upgrade for innovation. Consequently, they implement innovation management systems to become an innovation organization, which can harvest the ideation potential of their stakeholders. This is a complex task with company specific requirements, which should be done systematically. A 10 step implementation roadmap was proposed in the InoSuit Project, applied successfully to several companies in Turkey. It was seen that different approaches were required in different companies.

\section{References}

Acs, Z. J., \& Audretsch, D. B. 1988. Innovation in large and small firms: an empirical analysis. The American Economic Review, 678-690.

Ahmed, P. K. 1998. Culture and climate for innovation. European Journal of Innovation Management, 1(1), 30-43.

Albors-Garrisos, J., Ignacio, J. \& Peiro, A. 2018. Innovation management techniques and tools: Its impact on firm innovation performance, International Journal of Innovation Management, 22(6):1-31

Argyris, C., \& Schon, D. 1991. Participatory action research and action science compared, in W.F. Whyte (ed.), Participatory Action Research, pp. 85-96., Sage-London.

Bear, D. J. 2006. The quest for innovation: a global study of innovation management, 2006-2016. American Management Association.

Birkinshaw, J., Hamel, G., \& Mol, M. J. 2008. Management innovation. Academy of Management Review, 33(4): $825-845$.

Bower, J. L., \& Christensen, C. M. 1995. Disruptive technologies: catching the wave. Harvard Business Review 73(1): 43-53.

Cassell, C., Watkins, K. 1999. Action research: Explaining the diversity, Human Relations, 59 (6): $783-814$.

CEN 2013. CEN/TC 389 Innovation Management, Part 1: Innovation Management System. Technical Specification (TS) of the European Committee for Standardization (CEN), $\quad$ Nr. CEN/TS, 16555-1:2013.

Chao, R. O., \& Kavadias, S. 2008. A theoretical framework for managing the new product development portfolio: When and how to use strategic buckets. Management Science, 54(5): 907-921.

Christensen, C. M. 2013. The Innovator's Dilemma: When New Technologies Cause Great Firms to Fail. Reprint Edition. Boston, Massachusetts: Harvard Business Review Press.

Conforto, E. C., Salum, F., Amaral, D. C., da Silva, S. L., \& de Almeida, L. F. M. 2014. Can agile project management be adopted by industries other than software development? Project Management Journal, 45(3): 21-34.

Cooper R. G. 1990. Stage-gate systems: a new tool for managing new products. Business Horizons, 33(3): 44-54. 
Ç. Üçler - R. I. Yavuz 11/1 (2019) 189-201

Cooper, R. G. 2008. Perspective: The stage-gate ${ }^{\circledR}$ idea-to-launch process-update, what's new, and nexgen systems. Journal of Product Innovation Management, 25(3): 213-232.

Cooper, R. G. 2011. "Perspective: The innovation dilemma: how to innovate when the market is mature" Journal of Product Innovation Management, 28(1): 2-27.

Dickens, L., Watkins, K. 1999. Action research: Rethinking Lewin, Management Learning, 30(2): 127-140.

Eden, C., Huxman, C. 1996. "Action research for management research" British Journal of Management, 7:75-86.

Ekmekci, U., \& Pasin, M. 2016. InoSuit Project. Report of the methodology workshop of InoSuit. İstanbul: TiM.

FTSE Russell 2017. Industry Classification Benchmark: Structural enhancements to the industry categorization framework.

Gudmundson, D., Tower, C. B., \& Hartman, E. A. 2003. Innovation in small businesses: Culture and ownership structure do matter. Journal of Developmental Entrepreneurship, 8(1): 1-17.

Gunasekaran, A. 1999. Agile manufacturing: a framework for research and development. International Journal of Production Economics, 62(1-2): 87-105.

Hansen M. T., \& Birkinshaw, J. 2007. The Innovation Value Chain. Harvard Business Review, 85(6): 121-130.

Humphrey, J., \& Schmitz, H. 2002. How does insertion in global value chains affect upgrading in industrial clusters? Regional Studies, 36(9): 1017-1027.

Ionescu, M. A., \& Bratosin, Ş. 2009. Desirable typologies of organizational culture in quality management implementation. Communicational findings. Management $\mathcal{E}$ Marketing, 4(3):77-84.

Jacobides, M. G., Knudsen, T., \& Augier, M. 2006. Benefiting from innovation: Value creation, value appropriation and the role of industry architectures. Research Policy, 35(8): 1200-1221.

Johnson, S. 2010. Where Good Ideas Come From: The natural history of innovation. New York, NY: Riverhead Books.

Karlsson, M. 2013. Who needs a standard for innovation management? Towards a management system standard (MSS) for innovation. Helsinki, Germany: XXIV ISPIM (International Society for Professional Innovation Management) Conference.

Kearny A. T. 2017. Innovation - A.T. Kearney. The IMP3rove. European Innovation Management Academy.

Koen, P. A. 2007. The fuzzy front end for incremental, platform and breakthrough products. The PDMA Handbook of New Product Development, 2nd Edition, Chapter 6: 81-91. Hoboken, New Jersey: Wiley.

Koshy, E., Koshy, V., Waterman, H. 2020. Action research in healthcare. Sage-London.

Kurt, O. E., Ucler, C., \& Vayvay, O. 2017. From ideation towards innovation: pillars of front-end in new product development. Press Academia Procedia, 5: 71-79.

Lewin, 1946. Action research and minority problems, Journal of Social Issues, 143-153.

Mandić, V. 2014. Methodology for innovation management. WBCInno project, EU Tempus Programme. Kragujevac, Serbia: Inter Print, University of Kragujevac.

McDermott, CM \& O'Connor, GC. 2002. Managing radical innovation: An overview of emergent strategy issues. Journal of Product Innovation Management, 19(6): 424-438.

Morris, L. 2011. The innovation master plan: the CEO's guide to innovation. Walnut Creek, CA, USA: Innovation Academy.

Nieto, M. J., \& Santamaría, L. 2010. Technological collaboration: Bridging the innovation gap between small and large firms. Journal of Small Business Management, 48(1): 44-69.

Nonaka, I., Toyama, R., \& Konno, N. 2000. SECI, Ba and leadership: a unified model of dynamic knowledge creation. Long Range Planning, 33: 5-34. 
Osterwalder, A., \& Pigneur, Y. 2010. Business Model Generation: A handbook for visionaries, game changers, and challengers. Hoboken, New Jersey, USA: John Wiley \& Sons.

Phaal, R., Farrukh, C. J., \& Probert, D. R. 2004. Technology road mapping-a planning framework for evolution and revolution. Technological Forecasting and Social Change, 71(1): 5-26.

Pieterse, A. N., Van Knippenberg, D., Schippers, M., \& Stam, D. 2010. Transformational and transactional leadership and innovative behavior: the moderating role of psychological empowerment. Journal of Organizational Behavior, 31(4): 609-623.

Sawhney, M., Wolcott, R. C. \& Arroniz, I. 2006. The 12 different ways for companies to innovate. MIT Sloan Management Review, 47(3): 75.

Stamm, B. v. 2003. The innovation wave: meeting the corporate challenge. England: Wiley \& Sons Ltd.

Teece, D. J. 1996. Firm organization, industrial structure, and technological innovation. Journal of Economic Behavior \& Organization, 31(2): 193-224.

Thomke, S., \& Reinertsen, D. 1998. Agile product development: Managing development flexibility in uncertain environments. California Management Review, 41(1): 8-30.

TIM 2016. Türkiye İnovasyon Stratejisi 2023: İhracat Odakl İnovasyon ile Rekabet Gücünü Arttırmak. İstanbul: TIM.

TIM 2017. InoSuit - Innovation Focused Mentoring Project. tim.org.tr/tr/inosuit-inosuit-inovasyon-odaklimentorluk-projesi.html.

Tsekouras G., Meier C., Sutkus A., \& Wolf, A. 2014. The smE-MPOWER business innovation roadmap methodology: A methodological approach for establishing in a participative way a roadmap for business innovation in SMEs. Technical Results Paper, smE-MPOWER Project of the EU (ETIS-CT-2005023401).

Ucler, C. 2017. Intelligent assignment in clusters to enhance collaboration and innovation. Journal Manufacturing Technology Management, 28(5): 554-576.

Ucler, C., \& Adiloglu-Yalcinkaya, L. 2018. Innovation management system: what is and how to establish it? A Critical Review of Social Sciences: Theory and Practice. ISBN 978-9-3810-4328-8.

UND 2018. TIM İnoSuit - İnovasyon Odaklı Mentorluk Programı. https://www.und.org.tr/tr/20905/tim-inosuit--inovasyon-odakli-mentorluk-programi

ÜSIMP 2017. İnovasyon Karnesi. Üniversite Sanayi İşbirliği Merkezleri Platformu, çevrimci inovasyon değerlendirme anketi. https://usimpinovasyonkarnesi.com.tr/.

Vaccaro, IG, Jansen, JJ., Van Den Bosch and Volberda, HW. 2012. Management innovation and leadership: The moderating role of organizational size, Journal of Management Studies, 49(1): 28-51.

Van Dyne, L., \& LePine, J. A. 1998. Helping and voice extra-role behaviors: evidence of construct and predictive validity. Academy of Management Journal, 41(1): 108-119.

White, M. A., \& Bruton, G. D. 2010. The Management of Technology and Innovation: A Strategic Approach. 2nd Edition. Mason, OH, USA: Cengage Learning. 